\title{
Brandom's inferentialist Theory and the Meaning Entitlement Connection
}

\begin{abstract}
Alessia Marabini
ABSTRACT

According to Brandom's conceptual role semantics, grasping a concept involves a commitment to drawing certain inferences. This is a consequence of the inferentialist thesis that the meaning of a term is given by its justification through assertibility conditions. Inferential commitments stem from a material notion of inference which underwrites human rational discourse and activity. In this paper I discuss a problem of Brandom's semantics allegedly exposed in an argument by Paul Boghossian against Dummett's and Brandom's substantive conception of meaning. I contend that Boghossian's analysis is dubious because it overlooks an important difference between Dummett's and Brandom's positions related respectively to a monotonic and a non-monotonic view of the norm underwriting meaning.
\end{abstract}

$\S 1$.

As an essential part of his project to defend a conceptual role semantics, Brandom (2000) has offered an account of how we can grasp a concept. Grasping a concept, for Brandom, involves a commitment to drawing certain inferences. This in turn requires endorsing and defending the inferential commitments implicit in the concepts that these inferences employ. According to Brandom, a conceptual content can be said substantive when it leads to inferences that are valid in virtue of the contents of the words featuring in them because of their material properties (i.e. the properties of the objects these words refer to). Brandom's view depends on the inferentialist thesis that the meaning of an expression is given by its justification through assertibility conditions. Following Boghossian (2003a and 2003b), I call the particular kind of connection between meaning and assertibility conditions the Meaning Entitlement Connection, in short MEC.

In this paper, I focus on two alleged problems of Brandom's MEC presented in an argument by Paul Boghossian (2003a and 2003b) against both Dummett's and Brandom's substantive conception of meaning. In particular, I concentrate on Boche-like concepts, which give rise to this criticism (where 'Boche' is derogative term standing for 'German' and meaning 'cruel German'). Boghossian claims 
that Brandom's MEC doesn't allow for disagreement about the use and the content of Boche-like concepts and that it disallows knowledge extension required by new empirical information. I will cast doubts on both charges. I will contend that Brandom's theses about the non-monotonic character of the pragmatic normativity related to his substantive notion of meaning are immune to these objections because they don't fit the MEC that Boghossian attributes to Brandom. Boghossian's analysis is dubious because it overlooks an important difference between Dummett's and Brandom's views on these matters.

Part of the paper is devoted to discuss Boghossian's proposal of a new kind of Meaning Entitlement Connection (MEC*) as a possible solution of a revised MEC in light of those difficulties. This is supposed to be based on a different normative and not substantive notion of meaning.

This article is organized as follows: $§ 2$ Introduces Brandom’s view of broad inferentialism as linked with a material notion of inference and clarifies what it is like to have conceptual content on this view. $§ 3$ Expands on Brandom's model of practice of assertion which turns out to be involved in Brandom’s inferential semantics. §4 Introduces Boghossian’s criticism based on Boche-like concepts of Brandom's alleged conception of substantive content involving material inference commitments. $\S 5$ Details Boghossian's description of Brandom's and Dummett's alleged MEC. §6 Discusses Boghossian’s MEC* as a tool to solve the problem of Boche-like concepts. §7 Suggests that Boghossian's criticism of Brandom's MEC is flawed because it overlooks an important difference between Dummett's and Brandom's substantive views of meaning. $\S 8$ Draws the conclusions.

According to Brandom, conceptual content is accounted for by a kind of rationality which depends on Brandom's particular conception of material inference. Let me give a brief characterization of it. Brandom says that conceptual content is explained by 
1) its role in reasoning (cf. Brandom 2000: 72)

and

2) it takes the form of a holistic approach to concept meaning.

These features identify what he calls the inferential demarcation of conceptual (cf. Brandom 2000: 60).

But Brandom's view is distinct from other forms of inferentialism also because of:

3) the characterization of inference as material inference,

which gives rise to the so-called broad inferentialism. This approach conceives of inference as depending on the words' content, and thus in a sense broader than what seems to be implied by a notion of formally valid inference, hinging on a mere logical calculus.

A formally valid inference is understood in terms of a conditional that makes the conclusion "detached" and that is assumed to be an implicit premise of the argument. For instance, an inference of the kind:

It's raining. Therefore, the streets will be wet

is generally considered to be an enthymeme, as implicitly involving the conditional 'If it's raining, then the streets will be wet' as a premise. With this implicit premise, the inference is an instance of the formally valid schema of conditional detachment. ${ }^{1}$

1 A problem with this view, called by Sellars the received dogma (cf. Brandom 2000), is that it is too narrow. For not just all apparently correct inferences are based on this form. Furthermore, this view seems to take what Dummett calls the retrograde step, which elicits the problem discussed by Lewis Carroll in his famous paper "Achilles and the Tortoise". 
On the contrary, for Brandom's broad inferentialism, a material inference doesn't involve any implicit suppressed premise. For instance, one's asserting 'Pittsburgh is to the east of Princeton' enables one to materially infer from it 'Princeton is to the west of Pittsburgh'. And from 'Lightning is seen now' it is materially inferable 'Thunder will be heard soon'. These inferences are material because they depend on, not their logical-formal articulation, but the contents of some words featuring in the involved claims.

A material inference is also described by Brandom as a kind of inference whose correctness determines the conceptual content of premises and conclusions. The contents of the words east and west in the first inference above and the contents of the words lightning and thunder in the second are those that make, respectively, the two inferences appropriate. And, in turn, endorsing these inferences is part of grasping the concepts east, west, lightning and thunder (cf. Brandom 2000: 72).

This view together with the thesis that content is explained by its role in reasoning, leads to in Brandom terms - a broad notion of commitment. This happens in virtue of another important distinction about conceptual content. This is the distinction between the notion of a mere behavioural disposition and the one of understanding a conceptual content. While the first refers, for Brandom, to a purely causal connection, the second refers to a practical ability: the one of giving and asking for reasons. Thus, for instance, the use of the non-inferential perceptual term 'red' in the statement 'This is red' uttered by a parrot is an example of behavioural disposition as mere a mechanical response to a stimulus. For the parrot is unable to ask for and give reasons in response to its use of 'red'. On the other hand, actual understanding the content of red for a person uttering 'This is red' requires the above mentioned ability. We wouldn't say that the parrot possesses the mastery of the concept of red from its

Formal valid inferences, in Brandom's view, are just one kind of valid inference. For inference can be explained only in a broad sense, in accordance with broad inferentialism. With 'broad inferentialism' Brandom means the view according to which we can speak of an inferential commitment from circumstances of application of a concept to consequences of its use even in the case of concepts, like red, that have non-inferential circumstances of application, or like ought, which manifest non-inferential consequences of use. This view is opposed to narrow inferentialism, which corresponds to the hyperinferentialist view that inferential articulation is strictly necessary. This explains why formally valid inference can be accounted for by material inference, and not the other way round. 
mere uttering 'It's red', for its ability is not a cognitive matter. Indeed the parrot doesn't possess the mastery of the expression 'red' because, for instance, it is unable to infer from the statement 'It's red' other statements, such as 'It's not green'.

An important consequence of this view is that understanding a concept involves always a commitment to drawing inferences. For understanding, in accordance with the previous considerations, requires interpreting as inferential also concepts like red which, as we have seen, are not strictly inferential as regards to their circumstances of application, and concepts for normative vocabulary, like ought, which are not strictly inferential as for their consequences of application (cf. Brandom 2000: $21)^{2}$

Commitment so conceived has consequences about the way to understand meaning and content, and produces that which is called by Brandom a substantive notion of meaning. This notion intends content as given by the set of inferential commitments according to a broad version of inferentialism and material inference.

Substantive meaning is the focus of my argument here. For according to some critics it is affected by serious difficulties. For instance, an alleged problem has been exposed by Boghossian's argument against Brandom's solution for the so called Boche-like concepts. Let me briefly introduce this issue.

'Boche' is a derogatory term for 'German', which roughly means 'Cruel German'; this expression is similar for instance to the term 'nigger' for black people in English, or 'terrone' for southern Italians in Italian. I have anticipated before that content is generally explained in Brandom's inferentialist approach as given by its circumstances and consequences of use. For what concerns logical terms, circumstances are intended as the way to introduce the relevant term in a language by inferentialism, the inferential articulation of a concept is a necessary condition, while for the 'narrow' version it is a sufficient condition. 'Strong' inferentialism introduces instead a broad inferential conception of the conceptual, as it admits non-inferential practical use as consequences or circumstances of concepts use like in 'ought' term or 'red' term cases (cf. Brandom 2000: 21). 
using other terms not involving it, while consequences are intended as the way to eliminate the term in favour of other expressions of the language.

'Boche' is a predicate rather than a logical connective. Furthermore, it is characterized by these introduction and elimination rules:

I-rule: If $x$ is German, then $x$ is Boche

and

E-rule: If $x$ is Boche, then $x$ is cruel

If these rules are implemented, it turns out that, for any $x$, if $x$ is German, then $x$ is cruel, which is clearly unacceptable.

This issue was first brought to light by another advocate of the inferentialist approach. In Dummett's original discussion, Boche-like concepts uncover the harmony problem — that is to say, the problem of lack of harmony between circumstances of application of the concept in terms of inferential antecedents and inferential consequences of its use (cf. Dummett 1991: 246-251). This type of problem arises in the first instance for purely formal concepts such as the tonk one, ${ }^{3}$ but also for concepts with material content such as Boche. So a challenge for Brandom's view is how to solve this difficulty.

3 'Tonk' is conceived of, in Prior (1960)'s example, as a new connective for which these introduction and elimination rules hold:

I-rule: $p \rightarrow(p$ tonk $q$ ) (if $p$, then $p$ tonk $q)$

and

E-rule: $(p$ tonk $q) \rightarrow \mathrm{q}$ (if $p$ tonk $q$, then $q$ ).

In accordance with tonk's rules, it is possible to infer any $q$ from whatever $p$, which looks absurd. The case of 'Boche' is slightly different. 
A key feature of Brandom's solution depends on the particular notion of assertibility conditions, which is strictly interwoven — in his view — with a normative pragmatic conception of meaning. My aim here is to show that, in spite of its presupposing a substantive conception of content, Brandom's solution is better and more forceful than Dummett's, which is based on the requirement of harmony. And this is so despite Boghossian's diagnosis and attack. Let me now explain this in some detail.

$\S 3$

An important feature of Brandom's inferentialism is that broad commitment is also intended to be closely related to a notion of pragmatic norm underwriting content, which corresponds to assertibility. Accordingly, an analysis of the normative 'ought' term constitutes a key part of Brandom's position (cf. Brandom 2000).

I have observed above that inferential commitments are given as assertibility conditions of a sentence uttered with a particular force. A peculiarity of Brandom's position with regard to this is a non-standard notion of assertion. Within the inferentialist approach, assertibility has been traditionally associated with truth, and conceptual content has been explained in terms of the truth conditions of a sentence uttered with assertoric force, in line with an "ideal" conception of content. The broader conception of inferentialism, on the contrary, introduces the variant of conceiving of assertibility as a kind of pragmatic norm governing practical reasoning, in line with a material notion of inference. Assertibility conditions can be interpreted as asking whether the speaker is blameworthy for having fulfilled the obligations that a given speech act requires. This is the reason why an analysis of the term 'ought' constitutes a central question for Brandom. The normative status at the basis of meaning and content can be divided into two aspects, which are respectively the commitment and the entitlement (cf. Brandom 2000: 125). The first being a kind of responsibility that the speaker must endorse in the use of that content in term of its consequences, while the second being a sort of justification in introducing it 
in judgments and assertions. In preserving a certain kind of entitlement a speaker will show himself or herself to give particular emphasis to a certain content.

For instance, a speaker who takes

1) If it's raining, I shall open my umbrella

to be entitlement preserving will also believe a set of inferences like the following:

$\mathrm{a}^{\prime}$. Only standing under the awning will keep me dry, so I shall stand under the awning.

$\mathrm{a}^{\prime \prime}$. Only remaining in the car will keep me dry, so I shall remain in the car.

(Brandom 2010: 90)

This pattern of inferences shows that the speaker is implicitly attributing a preference to the content staying dry.

Other different patterns of inferences are nonetheless associated to the same normative term 'ought'. In the case of

2) I am a bank employee going to work, so I shall wear a necktie,

entitlement (or commitment) to its conclusion is preserved by a different underwritten kind of norm, which is associated with a certain status: that of being a bank employee.

'Being an employee' is then a reason in the objective sense of good reason for action (cf. Brandom 2000: 91). It is a reason for a bank employee A to wear a necktie. Taking it to be a norm undertakes doxastic commitment to the claim that $\mathrm{A}$ is a bank employee. This means that this claim is a 
good reason for action, or wearing necktie. The norm here is expressed by a cluster of other norms connected to the first social institutional norm, that of being bank employee, such as:

b') I am a bank employee going to the work, so I will not wear a clown costume;

b") I am a bank employee going to the work, so I will comb my hair; and so on...

which constitute a pattern of inference.

Normative vocabulary like 'ought', 'prefer', 'obliged' is what makes explicit the endorsement of a pattern of material practical inferences. So that assertibility is explained here in terms of moves in a rule-game plus the variants of their different possible relations. For undertaking one commitment rationally obliges us to undertake others related to the first as its consequences, and these relations articulate the conceptual content or content of the commitment in terms of responsibility for an act of assertion. More importantly, different patterns of inference should be understood as corresponding to different sorts of practical norms.

One problem that this conceptual role semantic theory of content faces is how to preserve the stability of content while allowing in the meanwhile change in commitments and beliefs variations in the use of the same concept from speaker to speaker (cf. Brandom 2000: 29-40). The norm is for this reason conceived by Brandom as split up in two parts: the one that follows 'truth' and which can guarantee the aim of 'objectivity' in the practice of communication, and the one that preserves the contact with the speaker's experience of new facts and evidence, in terms of commitment and entitlement.

Nonetheless, the representational dimension of conceptual content is not only inferentially but also socially articulated. A second aspect of the practice of assertion is the 'critical' dimension which is linked with the necessity to assess the commitments. In fact, the attribution of beliefs to another 
speaker is given in terms of attribution of commitments and entitlements to him or her. While the objectivity of content in terms of truth can be explained as the subsequent attribution to oneself of the same commitments attributed first to others.

But this social character also introduces the possibility of a critical dimension of changing and vary beliefs. This fact can be explained by the interaction of the two normative dimensions upstream inferential antecedents and downstream inferential consequents of assertable contents, which lead to incompatibility and inclusive relations. So two assertable contents can be incompatible in case the commitment to one sentence, for instance 'this swatch is red', rules out entitlement to commitment to another asserted sentence, like 'this swatch is green'. On the contrary, they can be 'inclusive' when they provide relations among sets of sentences that correspond to inferential relations among the sentences. For instance, the content of the claim expressed by 'the swatch is vermillion' entails the content of the claim of the assertion of the sentence 'the swatch is red'. As everything incompatible with being red is incompatible with being vermillion.

A consequence of the kind of interaction between inferential antecedents and inferential consequences of two assertable contents that correspond to incompatibility and inclusive relations is also the triadic normative structure of rationality. ${ }^{4}$ The 'committive' relation, namely, the commitment preserving relation, is at the base of the deductive inference and reasoning, also corresponding to formally valid inference in the narrow sense. ${ }^{5}$ While the 'permissive' relation is conceived at the basis of inductive inference, 'incompatible' relation deals with modal inference, as it supports counterfactual reasoning, which holds in sets' incompatibility or — conversely — in inclusion relations.

\footnotetext{
4 Brandom emphasizes that these inferential consequence relation can vary in their strength: all incompatibility entailments are commitment-preserving, though not vice versa, and all commitment preserving inferences are entitlement-preserving, though not vice versa.
}

5 For a notion of narrow inferentialism see above footnote 2. 
This characteristic is of fundamental importance in explaining the change in beliefs and the different commitments involved in the use of the same concept by different speakers. And it is allowed by a non-monotonic conception of the norm underlying content and more generally human rationality. Indeed, it also explains why the fact that conjoining a premise incompatible with, for instance, the individual desire to stay dry would turn the inference into a bad one does not show that the desire was functioning as an 'implicit' premise of the inference, as a Davidsonian would say. More importantly, it does not show that the norm underlying content and that is expressed by the conditional is a bad one.

Brandom would claim, for instance, that the inference:

\section{B. It is raining}

$\therefore$ The streets will be wet

can be treated in the same way as the inference:
A. It is raining
$\therefore$ I shall open my umbrella

According to Brandom, the second inference is generally considered to be incomplete because the inference wouldn't go through if I didn't want to stay dry. The Davidsonian would conclude from this fact that this is so because 'I want to stay dry' is an implicit suppressed premise of the inference. It turns out that if we call $p$ the sentence 'It's raining', $q$ the sentence 'The streets will be wet', and $r$ the sentence 'I want to stay dry', it is as if the inference from $p$ to $q$ is a good one meant that the inference from $p \& r$ to $q$ must be a good one (cf. Brandom, 2000: 87) and, more importantly, the fact that the latter is not a good argument meant it that the first is not either. In addition, the Davidsonian would 
interpret the inference as including, as a 'detached' premise, a conditional having as antecedent $p \& r$ and consequent $q$. The conditional including ' $r$ ' would be, in this view, a prerequisite for the inference.

In Brandom's view, nonetheless, this can be so only if the material inference is meant to be monotonic, while this is not the case of material inference (at least in ordinary discourse and in many sciences, for instance special sciences like medicine, and often also in physics). This is a very important consideration. Take for example the following conditionals mentioned by Brandom:

5. If I strike this dry, well-made match, then it will light. $(p \rightarrow q)$

6. If $p$ and the match is in a very strong electromagnetic field, then it will not light. $(p \& r \rightarrow \sim q)$ 7. If $p$ and $r$ and the match is in a Faraday cage, then it will light. ( $p \& r \& s \rightarrow q$ ) 8. If $p$ and $r$ and $s$ and the room is evacuated of oxygen, then it will not light. ( $p \& r \& s \& t$ $\rightarrow \sim q) \quad$ (Brandom 2000: 88)

These conditionals show how it is possible to construct in reasoning inferential hierarchies with oscillating conclusions like the ones above. So they show how reasoning in ordinary discourse — as well as in many special sciences — is resolutely non-monotonic.

This requisite - non-monotonicity - constitutes a core peculiarity of the notion of pragmatic norm underlying broad content as it is allowed by a material notion of inference. This requisite depends on the need to intend conceptual content as a kind of norm which can guarantee simultaneously communication between individuals and subjective use of concepts within one's individual utterances. Not to mention evolution of content in front of new experiences.

Moreover, it explains why the same conditional 'if $p$ then $q$ ' ('If it's raining, then I shall open the umbrella') corresponding to the inference can in fact lead to a valid inference or, on the contrary, may not go through depending on other detached premises.

For instance a detached premise like $r$, where 

c) $r=$ 'I want to stay dry'

or the opposite

$$
\text { d) } r=\text { 'I don't want to stay dry', }
$$

would respectively reveal a compatibility relation with the premise of the inference — the antecedent $p$ of the conditional - or an incompatibility relation with that same premise. It is in fact valid in case $c$, where 'I want to stay dry' is compatible with premise $p$, 'if it's raining', and its conclusion $q$, 'I shall open the umbrella'. On the opposite case d), it turns out to be incompatible with premise $p$ and conclusion $q$.

Although the feature of conditionals just explained gives rise to different individual patterns of inferences form speaker to speaker, it is a particularity of Brandom's view that all this doesn't infect the norm as it is expressed by the conditional 'if $p$ then $q$ ' if it is meant as non-monotonic — that is, as not including as an implicit premise the sentence $r$. Simply adding $c$, or alternatively $d$, to the inference as a premise will produce a valid or invalid inference. That would mean considering also material and natural causes at the basis of content as interfering with inference validity and correctness of reasoning.

Notice how these observations contribute to explain the importance in Brandom's view of intending the commitment as a substantive notion. For an incompatibility inferential relation between premise and the desire to stay dry arises only when we consider the material proprieties — that is, physical and natural of the new added content ('staying dry').

In light of the previous considerations let me now return to the "harmony problem" yielded by the predicate 'Boche' introduced at the beginning of this paper. According to some critics (prominently 
Boghossian 2003b: 11 and 2003a), a difficulty for Brandom's views stems from the fact that material inference and the correlated notion of commitment seem to make it impossible to disagree on conceptual content. This would become apparent as we consider cases like the one of the Bocheconcepts in ordinary language, which are well-known to Dummett and other scholars, Brandom included.

The reason of the difficulty — according to Boghossian — is the very thesis that meaning is a substantive notion due to the role that material inference plays within it. For this thesis doesn't take into account the possibility of knowledge extension given new experience. Moreover, it doesn't explain how it is possible genuine disagreement about commitments one would not like to endorse. And the reason of all this seems ultimately to be attributed to the alleged lack of a purely linguistic version of concept's definition of meaning, which Boghossian's alternative view would instead be able to supply.

Despite this charge, let me now show that Brandom's views - unlike Dummett's — do preserve the possibility of disagreement. Let me first go back to Dummett's notion of harmony to elucidate how it features in Brandom's view. Afterwards, I will go through Boghossian's argument. In the last section I will show in what sense Brandom's solution is different from Dummett's, and why it is in fact immune to Boghossian' criticism.

Concept use in assertions, in Dummett's inferentialist view, can be seen as the capacity to draw inferences involving it. The demand of harmony between circumstances and consequences of a concept application is expressible as the requirement that the addition of a new term to a language produce a conservative extension. But this addition produces a conservative extension if and only if it doesn't enable new inferences involving old expressions already present in the language that were not allowed before introducing the new concept. Accordingly, for Dummett, 'Boche' doesn't appear to be conservative with respect to the meaning of the concept 'German', which is involved in circumstances of application of the concept and included in the original language. 
Whereas, according to Dummett, what goes wrong with the Boche-concept is that its addition to the rest of language constitutes a non-conservative extension, for Brandom the Boche-concept only shows that this expression — 'Boche' — has substantive content. This means that it implicitly involves a material inference that is not already implicit in the contents of other concepts being concurrently employed $^{6}$ — in particular, the concept of German. Thus the question to be answered is the following: are the inferences that imply ought to be endorsed? The focus of our attention must thus shifts to an analysis of the functioning of the term 'ought' in ordinary discourse.

Let me now deal with the second part of the criticism — that is to say, Boghossian's attack on Brandom's solution given in terms of a substantive notion of meaning.

I have emphasized up to this point how the relation between material inferential commitments and entitlements among contents, in terms of compatibility and incompatibility relations is what amounts to, for Brandom, a substantive conception of meaning. I mentioned before Boghossian's criticism of Brandom's solution to the Boche problem, which he makes depend on the particular kind of substantive conception of meaning involved in Brandom's alleged Meaning Entitlement Connection (MEC) (cf. Boghossian 2003b: 11). In light of my previous observations, let me now concentrate on Boghossian's interpretation of the alleged MEC attributed to Peacocke, Dummett and Brandom, to ascertain whether its substantive character — in Brandom's terms — really fails to give an account of disagreement.

Boghossian's theory can be placed among a cluster of theories of analyticity that, even through different strategies of solution, are similar with respect to a common approach labelled 'semantogenetic' (cf. Horwich 2000: 151). Their shared feature is the idea of a stipulation as a link between an 
inferential rule and a term which meaning is constitutive of. Knowledge of the truth of this kind of definition, or stipulation, is said to be given independently of experience, so a priori. It is then given an entitlement to the inferential rule figuring in the stipulation. In synthesis, analyticity is given by all this.

The central point concerns the way in which meaning is provided. Some accounts refer to how it is "used" in discourse, as a path through which we could distinguish the right stipulations. So we could recognize the genuine constitutive inferential rules of meaning, among others not constitutively relevant to it. A chief problem is so that of explaining how acceptance of genuine stipulations is possible (cf. Horwich 2000 and Marabini 2013). Rather than requiring an explicit decision regarding those selected inferences constitutive of meaning, among a cluster of inferences involving that term, Boghossian opts for an implicit definition.

The strategy followed by Boghossian avoids acceptance by introducing a link between the notion of acting according to a rule and a belief as a mental state. Although this strategy is a priori, it does not require a previous justification for meaning. Rather, a different kind of weak, fallible a priori is being introduced, which can better be described as a kind of general "indefeasibility", rather than a logical impossibility of its falsity (cf. Casullo 2005). Defeasibility depending on new contrary evidence isn't however ruled out. This is so because of the presence of cognitive blind spots relative to human nature and rationality in general.

I cannot go deeper into the question of the a priori, as it is not central to my argument. I'll concentrate now on Boghossian's criticism of Brandom's position. One of the problems of Brandom's view (which Boghossian assimilates to MEC) is — according to Boghossian — that it doesn't appear true that if my taking A to be a reason for believing $\mathrm{B}$ is constitutive of my believing $\mathrm{B}$, this automatically absolves me of any charge of epistemic blameworthiness. As there are cases in which acceptance of an inference is written in the possession condition of a concept but where it is clear that the inference is not one to which the thinker is entitled to (Boghossian 2003: 241). Prior's tonk 


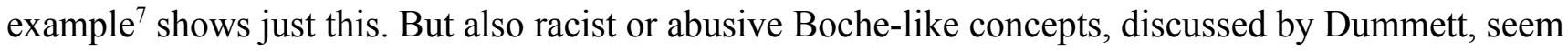
to expose the same problem, as it has been stressed before. For instance, a thinker possesses the concept of Boche just in case the thinker is disposed to infer according to the concept's introduction and elimination described before.

Thus Dummett and Brandom's MEC — in Boghossian's view — should be described as given by rules of respectively introduction and elimination, which form a theory $\mathrm{T}$ of the concept, seen as the constitutive rules for 'Boche'. Our stipulation for the term meaning would result in something of this kind:

\section{T (Boche): (1) $G x \rightarrow B x \&(2) B x \rightarrow C x$}

$\mathrm{T}$ is a theory for 'Boche' given by its introduction and elimination rules. Yet Boghossian stresses that no one is entitled to the view that all Germans are cruel, but that is exactly what would be implied by the MEC (cf. Boghossian 2003b: 10 and Boghossian 2003a: 242). According to Boghossian, the problem with this approach to MEC is that it requires a commitment to the existence of the property corresponding to the concept, in grasping its introductory and eliminatory rules. Problems are more evident with concept that we would never commit to, like our Boche, of a racist and immoral kind for many of us.

Boghossian's proposal is to restrict the MEC to just certain concepts from which the entitlement really flows (cf. Boghossian 2013a: 242). This general way of conceiving of MEC is strongly modified by Boghossian in a way that depends on its conception of the normativity of meaning, not strictly correctness-based.

Let me explain Boghossian's proposal in more detail. I said above that his interesting strategy is that of giving a link between the epistemic state of acting according to a rule and a belief state. This 
link reflects the idea that what is primarily normative is a belief, as it has a link with the truth (for it is constitutive of belief its aiming at truth), whereas meaning is not genuinely normative. Meaning only derives its link with truth from belief. In this way, we derive a sort of modal ought that makes the content of belief like a norm for us without requiring additional state, like motivation and so on. So the kind of correctness involved here goes in the direction of inquiring the nature of the ought so generated from belief.

An important fact is that 'ought' might be intended in two ways (cf. Boghossian 2005). These appear to correspond to an absolute sense and a more relative sense of belief. Precisely:

1) 'ought' as corresponding to belief in an absolute sense (genuinely normative rule), as exemplified by the sentence

(AR) we ought to belief everything that is true,

and

2) 'ought' as corresponding to belief in a regulative, prescriptive sense (prescriptive rule, derived normativity), as exemplified by the sentence

(RR) if something is true, we should believe it.

Since (AR) is impossible for us to follow (because, as humans, we have limited capacities and we can't believe all that is true), we act in practice in accordance with (RR). Although (AR) is a principle of belief, as a matter of fact we act in accordance with a regulative (prescriptive) rule (RR). We adopt in fact some rules to approximate to principles that are impossible for us to follow. Meaning has a nature 
of this kind, even if it is indirectly tied also to belief in the first sense. From this it follows that since it is belief in the strong sense that is strictly connected to the truth, then, meaning, which is connected to belief in the second sense of belief, has a link to the truth only in this derivative way (cf. Boghossian 2005: 210). All this has some bearings on the way we conceive

a) rules (intended as prescriptive rules, of derivative normativity)

and

b) principles (i.e. the primarily normative rules).

An example of this difference makes its appearance in questions regarding the justification of our inferential and epistemic rules. ${ }^{8}$

8 Examples of inferential and epistemic rules and inferential and epistemic principles are the following:

Principles (normative rules)

(Epistemic)

(EP1) If $\mathrm{S}$ is in good lighting conditions and ..., then if it visually appears to $\mathrm{S}$ that there is an $x$ in front of her, $\mathrm{S}$ is prima facie justified in believing that there is an $x$ in front of her.

(Inferential)

(EP2) If $\mathrm{S}$ is justified in believing $p$ and in believing 'if $p$ then $q$ ', and $\mathrm{S}$ infers $q$ from $p$, then $\mathrm{S}$ is prima facie justified in believing $q$.

Rules (prescriptive rules)

(Epistemic)

(ER1) If lighting conditions are good and ..., and it visually seems to you as if there is an $x$ in front of you, then believe that there is an $x$ in front of you.

(Inferential)

(ER2) If you are justified in believing that $p$, and in believing that 'if $p$, then $q$ ', then believe $q$ or give up one of the other beliefs.

ER1 and ER2 are examples of $R R$ normativity, while EP1 and EP2 are examples of normativity of $A R$ rules kind. In Boghossian's view, EP1 and EP2 encode objective facts inaccessible to us, but which we should think of as "real" any way, if we want to allow for true beliefs. 
Since the notion of the norm underlying meaning has been clarified, let's go back to Boghossian's revised notion of MEC, now called MEC*. One important feature of our concepts appears to be that of permitting us to disagree about their extensions. For example, for ordinary scientific terms like 'neutrino', we don't think of the rules of our possession condition of the concept as corresponding to the propositions that would be actually believed by a proponent of neutrino's theory. Rather, we think of these rules as corresponding to the propositions that one who were conditionalising on the truth of neutrino's theory would be willing to believe.

Thus, the revised $\mathrm{T}$ theory for 'Boche', also called ' $\# f$ ', is represented here by a conditional which Boghossian borrows from Carnap. According to Boghossian's view, the link between the expression ' $f$ ' of a concept and its theory ' $\# f$ ', thought of as a cluster of inferences characterized by the introduction and elimination rules, is now a normative commitment which characterizes the expression ' $f$ ' in first instance as a principle. This should have the advantage of giving an account of the openness of the meaning of ' $f$ ' and its continuous evolution.

The new form of the theory \#f for Carnap's conditional expressing meaning, namely:

$$
\text { (M) (马x) } f x \rightarrow \# f,
$$

bears on the way to intend the constraint that allows for the selection of the sentences, among all those including ' $f$ ', which are relevant to determine the meaning of ' $f$ ' (cf. Wright and Hale 2000). Here ' $f$ ' is the expression of a concept, for instance Boche, while the theory $\# f$ for ' $f$ ' is given by its introduction and elimination rules: I-rule, E-rule of the concept denoted by ' $f$ ' following the inferential Dummettian manner in a Gentzen Natural Deduction fashion.

According to Boghossian's MEC*, our T theory is split up in two parts: 
S) $(\exists x) f x$

[There exists a property for ' $f$ ']

A Carnap conditional ${ }^{9}$

M) (ヨx) $f x \rightarrow \# f$

[If there exists a property for ' $f$ ', then its theory is given by $f$-introduction and $f$-elimination rules].

Accordingly, the alleged Dummett-Brandom

T (Boche): (1) $G x \rightarrow B x \&$ (2) $B x \rightarrow C x$

turns into this proposition:

$\mathrm{T}($ CondBoche): $\exists F \mathrm{~T}(F) \rightarrow \mathrm{T}($ Boche $)$

[If there is a property $F$ such that $\mathrm{T}(F)$, then this property is $\mathrm{T}$ (Boche), which corresponds to the inferential rules stated in T for 'Boche']

(Boghossian 2003a and 2003b: 13-14)

This corresponds to the Carnap linguistic M conditional mentioned above.

A novelty of this conception of definition is that the cluster of inferences which constitute the \#f theory — i.e. the introduction and elimination rules — is not thought of as constitutive of a meaning conceived of as a substantive notion, in Brandom and Dummett's fashion. Rather, this cluster of

9 Carnap conditional is borrowed by Boghossian from Carnap's analysis of the meaning of theoretical concepts like temperature. A theory of meaning for these scientific terms results here as factorized in two parts of which one is the conditional (cf. Carnap 1956, 1958, 1963 and 1966) 
inferences is intended to be — in line with a non-substantive linguistic conception of meaning — an 'open' notion.

According to Boghossian, the Brandom-Dummett's substantive notion requires a commitment to the belief in the inferences that define the meaning of the relevant concept/term. This would involve believing that the Germans are cruel every time the expression 'Boche' is used, perhaps even when it is used to express just disagreement on this concept's extension.

By replacing it with a genuinely normative conception of meaning, it becomes possible to think of the possession condition of the concept of 'Boche' as given only by the linguistic conditional M alone, and not by $\mathrm{S}$ as well, which constitutes the empirical, substantive content. Now it becomes possible to wonder whether there is anything which falls under it and disagree about whether there is.

For Boghossian, this view characterizes non-defective concepts, which is what can answer the challenge of Boche-like concepts that was first posed by Dummett and then Brandom's inferentialist theory in making evident the consequences that endorsing the required commitments was leading to.

Inferences prove then constitutive of the linguistic, rather than material, norms underwritten by the $\mathrm{M}$ conditionals expressing meaning. So meaning is expressed by the norm underwritten by the relation expressed by the entire conditional. This view corresponds, for Boghossian, to a new version of Meaning Entitlement Connection (MEC*) (cf. Boghossian 2003: 16), according to which entitlement would follow from a more genuine conception of meaning and inferentialism.

$\S 6$.

Let me make some remarks. As we have seen, for Brandom, the norm of rationality is not monotonic. Take for instance the case of the bank employee considered above in $\S 3$. Here, this norm is the one underwritten by a cluster of inferences of the same kind which refer in that example, to the institutional role of a 'bank employee' taken into account. Moreover, it is made explicit by terms like 'ought'. The case looks not so different from Boghossian’s M conditional conception of content. 
As we have seen, the kind of 'ought' underwritten by Boghossian M conditional expressing meaning normativity refers to the norm of belief. According to Boghossian, this norm is truth conducive, as the state of belief always aims at the truth (cf. Boghossian 2005).

Now, the norm of belief is the norm of a mental state which — for Boghossian — should not be conceived of as objective, according to a classic conception of objectivity which requires the belief in everything that is true (cf. Boghossian 2005: 210). For Boghossian, the objectivity of the principle requires the belief only of what is true, as we have remarked in $\S 5$. This different conception of the norm as representative of the objectivity of the principle, and then of the status of belief as a mental state, enables us to take into account — so to speak — the blind spots of human reasoning. Following an objective norm, according to Boghossian, doesn't mean being able to give account of all possible examples it grounds. Rather, it means being able to give account of the ones that the speakers are able to conceive of as human beings. These considerations bear on Boghossian's conception of the 'ought' at the basis of semantic content. Where this semantic content is, as we have seen, split in two components of which only the second represents the norm of belief, and so of the rationality grounding the normative conception of meaning. Given a normative and not substantive conception of meaning, a different kind of connection between meaning and entitlement follows. It leads us to the view that introduction and elimination rules — and more generally inferential rules - are constitutive of a linguistic norm characterizing meaning (MEC*), rather than meaning conceived as substantive (MEC) (cf. Boghossian 2003a: 244 and 2003b: 16), as it happens in Brandom's view.

Boghossian's view of meaning is intended to allow for disagreement on concept extension and factual import that are not genuinely taken into account in other conceptions of meaning and inferentialism, such as Brandom's. A problem arise nonetheless, in my opinion. For the M linguistic conditional expressing normative meaning of terms — like 'Boche' for instance — though more open than previous accounts of inferentialism, cannot take into account of new factual import. This is due to the particular nature of the theory T or \#f figuring in the consequent of Carnap's conditional. Note that 
Brandom's conditional, on the other hand, seems to allow factual import thanks to the non-monotonic character and its material notion of inference. But I will not pursue this issue here, as it is not central to my main focus.

\section{$\S 7$.}

My criticism of Boghossian's view is briefly this: Boghossian neglects an important difference between Dummett's and Brandom's conceptions of substantive meaning. This is due to a diverse notion of the norm underwriting it.

With regard to Boche-like concepts, Brandom doesn't seem to think that these cases display a problem for his view. Rather he thinks that these concepts reveal important features of meaning and conceptual content in relation to the commitments they lead to. For the apparent problem can be explained away simply in terms of acceptance or refusal of commitments. Brandom emphasizes that evaluating introduction and consequences of 'Boche' involves, not determining whether the inference is one that is already endorsed, so that no new content is really involved (as Dummett would put it) but, rather, determining whether that inference is one that ought to be endorsed. Dummett's notion of harmony implies that the Boche-like concept be only a conservative extension of previous concepts already involved in the theory before its introduction, but figuring in its introduction and elimination inferential rules.

The underlying idea proves, for Brandom, in some sense similar to the one underwriting the formally valid inference implying conditional detachment that I have previously considered to elucidate its difference with respect to material inference. An example can clarify this case. Given $p=$ 'it's raining', $q=$ 'the streets will be wet' and $r=$ 'There is an awning', there is no point, for Brandom, in deducing that from the fact that

$p \& r \rightarrow \sim q$ (if it's raining and there is an awning, then the streets will not be wet) 
one can derive that the norm expressed by the conditional

$p \rightarrow q$ (if it's raining, then the streets will be wet)

it's not a good argument (cf. Brandom 2000: 88). But this is, for Brandom, exactly what Dummett's mistaken argument of harmony risks to amount to, before the so called Boche-like concept fallacy.

Brandom's strategy, on the contrary, admits the possibility to intend Boche-like content as novel content in a way similar to the introduction in science of theoretical expression, like the term 'temperature'. Theoretical expressions are introduced by conditionals that don't require conditional detachment but that, at the same time, manifest a norm ceteris paribus.

This ceteris paribus requirement compatible with a non-monotonic character is what renders Brandom's normativity of meaning apt to talk about a same content while allowing disagreement and different individual perspectives on it. Brandom's strategy aims to propose an alternative to Dummett's requirement of harmony between circumstances and consequences of application of the concept. This difference is due to the diverse view of the norm underlying conceptual content, which amounts to a monotonic view in Dummett's requirement of harmony and a non-monotonic character in Brandom's notion of conceptual content. And the very same difference seems to me to distinguish, at the end, Brandom's inferentialism from Boghossian's critical approach.

This fact shows one more time the way in which Brandom thinks of his notion of commitment. For one could criticize a concept on the basis of substantial belief without allowing the inference from premises to conclusion. In this way one wouldn't in fact commit oneself to the inference from the obvious fact that there is someone $x$ who is German to the conclusion that $x$ is cruel. This move involves the idea that material inference commitments are a necessary part of the practices that include material doxastic commitment. "Harmony" then becomes, for Brandom, a question of which material 
inference and which concepts we ought to endorse (cf. Brandom, 2000: 75) without rejecting the conditionals representing the rules underwriting the use in communication of the concept Boche.

To go back to our case, there is no need, for Brandom, to refuse the conditional 'if $\mathrm{x}$ is Boche, then $\mathrm{x}$ is a cruel German' expressing the normative content of 'Boche' in order to use the term meaningfully while at the same time assessing it. What a speaker must do it is, rather, to decline to accept its validity by refusing to endorse the corresponding belief. The refusal would be, for Brandom, the result of an incompatibility relation coming out of an interaction between assertional inferences, the commitments, and consequential inferences, the entitlements to other inferences that the concept would lead to.

Therefore, for Brandom, the perceived problem doesn't consist in the concept of Boche turning out to be novel once we consider the material inferential commitments it involves. The perceived problem is, rather, that the commitments appear inappropriate so that we could not be entitled to them.

So let me now draw my conclusions. In Brandom's view, one who rejects a word such as, for instance, 'Boche' does so because one doesn't want to permit a transition from the grounds for applying the term to the consequences of doing so. A concept can be criticized if it involves a material inference not already implicit in the other contents employed, on the basis of substantive beliefs. With regard to this, Brandom makes an important observation:

Outside of logic, this is no bad thing. Conceptual progress in science often consists in introducing just such novel contents. The concept of temperature was introduced with certain criteria or circumstances of appropriate application, and certain consequences of application. As new ways of measuring temperature are introduced, and new theoretical and practical consequences of temperature measurements adopted, the complex inferential commitment that 
determines the significance of using the concept of temperature evolves. The proper question to ask in evaluating the introduction and evolution of a concept is not whether the inference embodied is one that is already endorsed, so that no new content is really involved, but rather whether that inference is one that ought to be endorsed. The problem with 'Boche' or 'nigger' is not that once we explicitly confront the material inferential commitment that gives the term its content it turns out to be novel, but that it can then be seen to be indefensible and inappropriate — a commitment we cannot become entitled to. We want to be aware of the inferential commitments our concepts involve, to be able to make them explicit, and to be able to justify them. But there are other ways of justifying them than showing that we were already implicitly committed to them before introducing or altering the concept in question.

(Brandom 2001: 71)

So, first of all, against Dummett's requisite of harmony, to respond to the criticism of the inferentialist approach depending on the Boche-like concepts, Brandom suggests here that there are ways to justify the commitments that our concepts involve that are quite different from showing (as Dummett would say) that we were implicitly committed to them before introducing the concept in question.

Second, in opposition to Boghossian's criticism, this passage emphasises an important aspect of the substantive conception of meaning undertaken by Brandom's argument. To begin with, a relevant question regards 'blindness'. The term refers — for Brandom — to what corresponds to blind spots of reasoning, namely, those parts of reasoning that the speakers must consider reliable without any inferential structure before being able to articulate them in patterns of inferences, such as the case of the terms 'red' or 'ought' considered above. Although in Brandom's view, their content structure depends on a material notion of inference that is a substantive conception of meaning, nonetheless Brandom's characterization of content is given in terms of the norm which underwrites it. But this norm, as I have indicated above, is not undermined in case the norm itself gives rise to an invalid 
argument when an implicit premise is added to the present premise. This fact — as Brandom remarks — doesn't show that the norm was an invalid one, and doesn't commit anyone to dropping it. Simply, it is still possible to treat it as a norm for which a ceteris paribus alleged propriety, except in particular cases, can still be preserved, but to indicate its non-monotonicity (cf. Brandom 2000: 88) An interlocutor could still discuss this conceptual content and evaluate it, simply he or she will not endorse it. What makes explicit the endorsement of a pattern of material practical inferences (practical rules) in appreciating or evaluating a norm is normative vocabulary, like 'ought' 'prefer' 'obliged'. I didn't stress this point earlier. However, it is important to emphasize that different patterns of inference should be understood as corresponding to different sorts of norms, underwriting content. And this doesn't preclude, in my view, the possibility of a disagreement on its extension, while all at once allowing meaning implementation and knowledge extension in a continuous comparison with experience.

\section{References}

Boghossian, P. (1997). 'Analyticity'. In R. Hale and C. Wright (ed.), A Companion to the Philosophy of Language. Oxford: Blackwell.

Boghossian, P. (2001). 'How are objective epistemic reasons possible?' Philosophical Studies 106: $340-380$.

Boghossian, P. (2003a). 'Blind reasoning'. Proceedings of the Aristotelian Society Sup. 77: 225-48. Boghossian, P. (2003b). 'Epistemic Analyticity: A Defense', Grazer Philosophische Studien 66: $15-$ 35.

Boghossian, P. (2005). 'Is Meaning Normative?' In C Nimtz and A. Beckermann (eds.) PhilosophyScience-Scientific Philosophy. Main lectures and Colloquia of GAP. 5. Fifth International Congress of the Society for Analytical Philosophy, Bielefeld, 2003. Mentis.

Boghossian, P. and C. Peacocke (eds.) (2000). New Essays on the A Priori. Oxford: OUP. 
Brandom, R. (1976). 'Truth and Assertibility'. The Journal of Philosophy 73: 173-149.

Brandom, R.(1998). Making it explicit. Cambridge, MA: Harvard University Press.

Brandom, R. (2000). The Articulation of Reasons. Cambridge, MA: Harvard University Press.

Carnap, R. (1956) 'The Methodological Character of Theoretical Concepts'. In H. Feigl, M. Scriven and G. Maxwell (ed.), Minnesota Studies in the Philosophy of Science, Vol. 1. The Foundations of Science and the Concepts of Psychology and Psychoanalysis, pp. 38-76. Minneapolis: University of Minnesota Press.

Carnap, R. (1958). 'Beobachtungssprache und theoretische Sprache'. Dialectica 12: 236-248.

Carnap, R. (1963). 'Carl Gustav Hempel on Scientific Theories'. In P. A. Schilpp (ed.), The Philosophy of Rudolf Carnap, pp. 958-966. La Salle: Open Court.

Carnap, R. (1966). Philosophical Foundations of Physics: An Introduction to the Philosophy of Science. New York, Basic Books.

Casullo, A. (2005). A Priori Justification. Oxford, Oxford University Press.

Dummett, M. (1991). The Logical Basis of Metaphysics. The William James Lectures, 1976 Cambridge Mass: Harvard University Press.

Horwich, P. (2000). ‘Stipulation, Meaning and Apriority”. In P. Boghossian and C. Peacocke (ed..), New Essays on the A Priori. Oxford: OUP.

Marabini, A. (2013). La concezione epistemica dell'analiticità. Un dibattito in corso. Roma: Aracne Editrice.

Prior, A. N. (1960). 'The Runabout Inference Ticket'. Analysis 21: 38-39.

Wright C. and B. Hale. (2000). 'Implicit Definition and the A Priori'. In P. Boghossian and C. Peacocke (ed..), New Essays on the A Priori. Oxford: OUP. 